\title{
Lyme disease: the promise of Big Data, companion diagnostics and precision medicine
}

\section{Raphael B Stricker' \\ Lorraine Johnson ${ }^{2}$}

'International Lyme and Associated Diseases Society, Bethesda, MD,

${ }^{2}$ LymeDisease.org, Chico, CA, USA

Video abstract

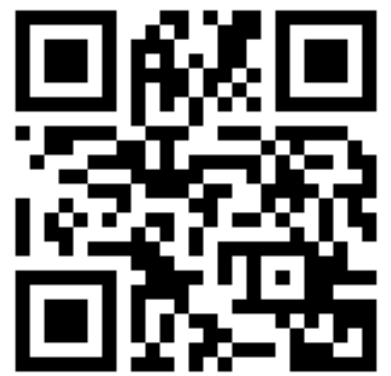

Point your SmartPhone at the code above. If you have a $Q R$ code reader the video abstract will appear. Or use: http://youtu.be/hMJAjVoysQ
Correspondence: Raphael B Stricker Union Square Medical Associates, 450 Sutter Street, Suite 1504, San Francisco, CA 94108, USA

Tel + I 4153991035

Fax + I 4I53991057

Email rstricker@usmamed.com
This article was published in the following Dove Press journal:

Infection and Drug Resistance

13 September 2016

Number of times this article has been viewed

\begin{abstract}
Lyme disease caused by the spirochete Borrelia burgdorferi has become a major worldwide epidemic. Recent studies based on Big Data registries show that $>300,000$ people are diagnosed with Lyme disease each year in the USA, and up to two-thirds of individuals infected with $B$. burgdorferi will fail conventional 30-year-old antibiotic therapy for Lyme disease. In addition, animal and human evidence suggests that sexual transmission of the Lyme spirochete may occur. Improved companion diagnostic tests for Lyme disease need to be implemented, and novel treatment approaches are urgently needed to combat the epidemic. In particular, therapies based on the principles of precision medicine could be modeled on successful "designer drug" treatment for HIV/AIDS and hepatitis $\mathrm{C}$ virus infection featuring targeted protease inhibitors. The use of Big Data registries, companion diagnostics and precision medicine will revolutionize
\end{abstract} the diagnosis and treatment of Lyme disease.

Keywords: HIV/AIDS, hepatitis C virus, Big Data, designer drugs, protease inhibitors

\section{Introduction}

Lyme disease caused by the spirochete Borrelia burgdorferi is the most common tickborne illness in the world today. ${ }^{1,2}$ While analysis of large data subsets (Big Data) has enhanced biomedical research over the past decade, ${ }^{3}$ the use of Big Data to analyze the incidence and severity of Lyme disease has been a challenging process, mainly due to ongoing controversy over the tickborne disease that is discussed in detail elsewhere. ${ }^{4,5}$ Prior to 2010 , most studies of Lyme disease included limited numbers of patients and were performed by researchers with specific agendas that often excluded patient input. The result was a skewed view of tickborne disease that often tended to trivialize both the number of infected patients and severity of patient symptoms. ${ }^{6,7}$ Furthermore, studies of extended treatment of Lyme disease using conventional antibiotic therapy featured small numbers of patients who received ineffective drug regimens for inadequate amounts of time. For example, the four randomized controlled trials sponsored by the National Institutes of Health enrolled a grand total of 221 patients. ${ }^{8}$ At the very least, these small studies were underpowered and failed to yield sufficient evidence to restrict further Lyme disease treatment. ${ }^{9}$

\section{Big Data}

Starting in 2010, a patient group called LymeDisease.org began to collect patient data via an interactive website. The first study based on this survey approach was published in 2011 and included responses from $>2,400$ patients. ${ }^{10}$ The study concluded that Lyme disease patients frequently endure extensive delays in obtaining an initial diagnosis, 
have poor access to health care, and suffer a severe burden of illness. A follow-up study was published in 2014 and included $>3,000$ patients with persistent Lyme disease symptoms known as chronic Lyme disease (CLD). ${ }^{11}$ The study concluded that

CLD patients have significantly impaired health-related quality of life and greater healthcare utilization compared to the general population and patients with other chronic diseases. The heavy burden of illness associated with CLD highlights the need for earlier diagnosis and innovative treatment approaches that may reduce the burden of illness and concomitant costs posed by this illness. ${ }^{11}$

Thus, these initial Big Data studies painted a dismal picture of the burden of illness and quality of life in patients with persistent Lyme disease symptoms.

LymeDisease.org has established a secure online registry called MyLymeData (www.mylymedata.org) with the goal of enrolling at least 10,000 Lyme disease patients for further Big Data investigations. This registry will provide detailed clinical information about patients who have been diagnosed with tickborne diseases by their health care providers. It will ultimately yield extensive information about B. burgdorferi morbidity, pathophysiology, genetic risk factors, and laboratory testing, and the registry will facilitate recruitment for future studies of precision treatment using "designer drugs", as outlined in the following.

Previous analyses based on the restrictive surveillance case definition employed by the Centers for Disease Control and Prevention (CDC) estimated that the annual rate of Lyme disease in the USA was $\sim 30,000$ cases per year. However, in 2013, the CDC published a trio of reports based on large insurance, laboratory, and practitioner databases. ${ }^{12}$ These reports represented the first government attempt to use Big Data to examine the incidence of tickborne disease, and the reports suggested that the annual rate of Lyme disease was $>300,000$ cases in the USA. ${ }^{13}$ This annual rate was more than ten times the number of cases reported using the limited CDC surveillance case definition, making Lyme disease six times more common than HIV/AIDS, 20 times more common than hepatitis $\mathrm{C}$ virus (HCV) infection, and 30 times more common than tuberculosis in the USA. ${ }^{5,14}$

Following the CDC reports confirming the increased annual burden of Lyme disease in the USA, a major Big Data study was performed at Johns Hopkins Medical Center. ${ }^{15}$ The study examined a database of 47 million persons enrolled in a wide range of US commercial health insurance plans. From this database, the authors identified 547,993 potential Lyme disease cases and analyzed 52,795 cases in more detail. They found that over $63 \%$ of treated Lyme disease cases had at least one diagnosis associated with chronic posttreatment Lyme disease syndrome, and these patients had 2.6-5.5 times the rate of fatigue, arthropathy, and neuropathy compared to matched controls. ${ }^{15}$ This finding implied that conventional antibiotic treatment failed in approximately two-thirds of Lyme disease cases, and the result contrasted sharply with previous small studies claiming that posttreatment Lyme disease syndrome and chronic complications of treated B. burgdorferi infection were rare or nonexistent. ${ }^{16}$ Thus, the study outcome based on Big Data highlighted the need for better treatment of Lyme disease.

The extensive burden of Lyme disease shown in these studies suggests that disease spread may be more complicated than previously thought. Although tick transmission of Lyme disease is well established, the discovery of new tick-associated Borrelia strains in arctic and equatorial locations has raised questions about the worldwide dissemination of Lyme disease beyond temperate zones, ${ }^{17-19}$ and the unknown risk of sexual transmission of the Lyme spirochete has recently received renewed attention. ${ }^{20}$ Animal models of B. burgdorferi sexual transmission in mice, dogs, and ticks have been described in the past, ${ }^{21-23}$ and further animal and human studies using sophisticated detection methods are now in progress. ${ }^{24}$ Whether this form of spirochete transmission is significant in Lyme disease remains to be determined, but the possibility of sexual transmission raises the question of how to treat a disease that may resemble HIV/AIDS in terms of infection risk and need for prolonged treatment.

\section{Companion diagnostics for Lyme disease}

One controversial aspect of Lyme disease involves testing for the tickborne illness. The standard CDC-approved algorithm involves two-tier serological testing using a screening enzyme-linked immunosorbent assay or immunofluorescence assay followed by a confirmatory Western blot. According to the $\mathrm{CDC}$, the commercial test kits must be cleared by the US Food and Drug Administration (FDA) to assure that the marketed kits are standardized. ${ }^{25}$ It is important to recognize, however, that FDA clearance only assures uniformity but not accuracy of the commercial test kits. Although these kits have a specificity of $99 \%$ and yield few false-positive results, they have poor sensitivity and miss more than half of Lyme disease cases. ${ }^{2}$ Thus, FDA-cleared commercial serological testing for Lyme disease is inadequate for the diagnosis of the disease. This deficiency has led to the development of novel approaches to B. burgdorferi testing using culture, molecular detection, and other techniques. Unfortunately, none of these novel techniques appears to be more sensitive than the inadequate commercial serological testing. ${ }^{1}$ 
To address the poor results of commercial testing, two modifications of the Lyme Western blot have allowed greater sensitivity and equivalent specificity compared to the two-tier algorithm. ${ }^{26}$ The first modification involves use of two target strains of $B$. burgdorferi in the Western blot instead of the single target strain in the FDA-cleared commercial kits. The second modification involves the use of alternate interpretation criteria derived from the peer-reviewed medical literature. ${ }^{27,28}$ With the use of these modifications, the sensitivity of the Western blot is increased to $97 \%$, while the specificity is $>97 \%$ when a confirmatory test is used. ${ }^{26}$ Although better companion diagnostic testing for tickborne disease may be developed someday, this simple adjustment to the FDA-cleared test method can significantly improve current Lyme disease testing and resolve much of the controversy over who needs treatment for Lyme disease.

\section{Precision treatment for Lyme disease}

B. burgdorferi is a relatively complex organism. The spirochete contains enzymes that facilitate tissue penetration and has the ability to form cystic structures and hide in biofilms. ${ }^{29-34}$ These properties allow the organism to persist in a variety of tissues and hostile environments and escape the reach of antibiotics. The ability of B. burgdorferi to infect privileged sites, such as the eye, synovium, and brain, may also contribute to persistence of the spirochete in human tissues, much like the agents of syphilis, tuberculosis, and HIV/ AIDS. ${ }^{1,2}$ Recent studies have shown that $B$. burgdorferi forms persister cells that can survive treatment with conventional antibiotics. ${ }^{35,36}$ The existence of these persister cells supports the view that CLD is associated with persistent spirochetal infection that requires more effective therapy.

Currently recommended antibiotic therapy for Lyme disease is based on monotherapy with one of three main antibiotic classes: penicillins, tetracyclines, and cephalosporins. Penicillins were first used clinically in 1942, and amoxicillin, the form most commonly used to treat Lyme disease, was introduced in 1972. Tetracyclines were first used clinically in 1948, and doxycycline was introduced in 1966. Cephalosporins were first used clinically in 1964, and intravenous ceftriaxone was introduced in $1977 .{ }^{37}$ It has become increasingly clear that these ancient antibiotics that have been used to treat tickborne infections for over 30 years are inadequate for effective therapy of Lyme disease. Furthermore, the trend in antimicrobial treatment of chronic infections is to use combination therapy, as seen with tuberculosis, HIV/AIDS, and HCV infection. ${ }^{38-40}$ Thus, better antimicrobial regimens for Lyme disease are urgently needed. Although one research group has suggested using "repurposed" antimicrobials to treat B. burgdorferi infection, ${ }^{36}$ this approach was unsuccessful in HIV/AIDS and HCV infection, and it seems clear that a better approach is needed for Lyme disease.

In examining pharmaceutical successes in treating HIV/ AIDS and HCV infection, a common theme has been the development and implementation of protease inhibitor therapy. ${ }^{39,40}$ Some targeted viral proteases resemble their bacterial counterparts, ${ }^{41,42}$ and it seems logical that this precision treatment approach would be beneficial in Lyme disease as well. A number of studies have characterized B. burgdorferi proteases, and these enzymes would be excellent targets for designer drugs to treat Lyme disease. ${ }^{43-46}$ For example, a study has shown that $B$. burgdorferi persister cells upregulate a protease called ClpP, and this protease would be a logical target for designer drug therapy. ${ }^{43}$ Another potential target is the $\mathrm{BbHtrA}$ protease, which contributes to the virulence and pathogenicity of the spirochete. ${ }^{44,45}$ A third potential target would be the $B$. burgdorferi Lon proteases that are involved in cellular homeostasis. ${ }^{46}$ Other B. burgdorferi proteases, such as HrpA, CtpA, LuxS, and FtsH, have recently been described, ${ }^{47-50}$ and with intense research these targets could be exploited to develop revolutionary precision treatments for Lyme disease. The effort would not be purely altruistic: protease inhibitor treatment of Lyme disease would likely outstrip the $\$ 18.5$ billion annual profit for HIV/AIDS drugs and the $\$ 4.5$ billion annual profit for HCV therapy.

\section{Conclusion}

In summary, studies using Big Data have elucidated the significant patient burden of Lyme disease in the USA and raised questions about the role that sexual transmission plays in this spirochetal illness. Commercial laboratory testing for the disease has been inadequate up until now, but better serological testing is readily available and next generation companion diagnostic testing is rapidly evolving. ${ }^{51}$ Precision medical treatment for Lyme disease can be developed using strategies that were successful in treating HIV/AIDS and $\mathrm{HCV}$ infection. The combination of Big Data, companion diagnostics and precision medicine provides a roadmap for the cure of Lyme disease.

\section{Acknowledgments}

The authors thank Phyllis Mervine and Pat Smith for online support.

\section{Author contributions}

All authors contributed toward data analysis, drafting and revising the paper and agree to be accountable for all aspects of the work. 


\section{Disclosure}

The authors report no conflicts of interest in this work.

\section{References}

1. Stricker RB, Johnson L. Lyme disease: the next decade. Infect Drug Resist. 2011;4:1-9.

2. Stricker RB, Johnson L. Lyme disease diagnosis and treatment: lessons from the AIDS epidemic. Minerva Med. 2010;101(6):419-425.

3. de la Torre Díez I, Cosgaya HM, Garcia-Zapirain B, López-Coronado M. Big Data in health: a literature review from the year 2005. J Med Syst. 2016;40:209.

4. Feder HM Jr, Johnson BJ, O'Connell S, et al. A critical appraisal of 'chronic Lyme disease'. N Engl J Med. 2007;357(14):1422-1430.

5. Stricker RB, Johnson L. Lyme disease: call for a "Manhattan Project" to combat the epidemic. PLoS Pathog. 2014;10(1):e1003796.

6. Stricker RB, Johnson L. The pain of chronic Lyme disease: moving the discourse backward? FASEB J. 2011;25(12):4085-4087.

7. Kullberg BJ, Berende A, van der Meer JW. The challenge of lyme disease: tired of the Lyme wars. Neth J Med. 2011;69(3):98-100.

8. Cameron DJ, Johnson LB, Maloney EL. Evidence assessments and guideline recommendations in Lyme disease: the clinical management of known tick bites, erythema migrans rashes and persistent disease. Expert Rev Anti Infect Ther. 2014;12(9):1103-1135.

9. Delong AK, Blossom B, Maloney EL, Phillips SE. Antibiotic retreatment of Lyme disease in patients with persistent symptoms: a biostatistical review of randomized, placebo-controlled, clinical trials. Contemp Clin Trials. 2012;33(6):1132-1142.

10. Johnson L, Aylward A, Stricker RB. Health care access and burden of care for patients with Lyme disease: a large United States survey. Health Policy. 2011;102(1):64-71.

11. Johnson L, Wilcox S, Mankoff J, Stricker RB. Severity of chronic Lyme disease compared to other chronic conditions: a quality of life survey. Peer J. 2014;2:e322.

12. CDC.CDC provides estimate of Americans diagnosed with Lyme disease each year [press release]. Atlanta, GA: Centers for Disease Control and Prevention; 2013 [August 19]. Available from: http://www.cdc. gov/media/releases/2013/p0819-lyme-disease.html. Accessed July 9, 2016.

13. Nelson CA, Saha S, Kugeler KJ, Delorey MJ, Shankar MB, Hinckley AF, Mead PS. Incidence of clinician-diagnosed Lyme disease, United States 2005-2010. Emerg Infect Dis. 2015;21(9):1625-1631.

14. Salinas JL, Mindra G, Haddad MB, Pratt R, Price SF, Langer AJ. Leveling of tuberculosis incidence-United States, 2013-2015. MMWR Morb Mortal Wkly Rep. 2016;65(11):273-278.

15. Adrion ER, Aucott J, Lemke KW, Weiner JP. Health care costs, utilization and patterns of care following Lyme disease. PLoS One. 2015;10(2): 0116767.

16. Wormser GP, Dattwyler RJ, Shapiro ED, et al. The clinical assessment, treatment, and prevention of Lyme disease, human granulocytic anaplasmosis, and babesiosis: clinical practice guidelines by the Infectious Diseases Society of America. Clin Infect Dis. 2006; 43(9): 1089-1134

17. Kumsa B, Socolovschi C, Raoult D, Parola P. New Borrelia species detected in ixodid ticks in Oromia, Ethiopia. Ticks Tick Borne Dis. 2015; 6(3):401-407.

18. Hvidsten D, Stordal F, Lager M, et al. Borrelia burgdorferi sensu latoinfected Ixodes ricinus collected from vegetation near the Arctic Circle. Ticks Tick Borne Dis. 2015;6(6):768-773.

19. Ehounoud CB, Yao KP, Dahmani M, et al. Multiple pathogens including potential new species in tick vectors in Côte d'Ivoire. PLoS Negl Trop Dis. 2016;10(1):e0004367.

20. Middelveen MJ, Burke J, Sapi E, et al. Culture and identification of Borrelia spirochetes in human vaginal and seminal secretions [version 1; referees: 1 not approved]. F1000Research. 2014;3:309.
21. Wright SD, Nielsen SW. Experimental infection of the white-footed mouse with Borrelia burgdorferi. Am JVet Res. 1990;51(12):1980-1987.

22. Gustafson JM. The in utero and seminal transmission of Borrelia burgdorferi in Canidae [PhD thesis]. Madison, WI: University of Wisconsin; 1993. Available from: http://search.library.wisc.edu/catalog/ocm29551629. Accessed July 9, 2016.

23. Alekseev AN, Dubinina HV. Exchange of Borrelia burgdorferi between Ixodes persulcatus (Ixodidae: Acarina) sexual partners. J Med Entomol. 1996;33(3):351-354.

24. Stricker RB, Middelveen MJ. Sexual transmission of Lyme disease: challenging the tickborne disease paradigm. Expert Rev Anti-Infect Ther. 2015;13:1303-1306.

25. CDC 2015. Lyme disease: two step laboratory testing process. Available from: http://www.cdc.gov/lyme/diagnosistesting/labtest/twostep/index. html. Accessed July 9, 2016.

26. Shah JS, Du Cruz I, Narciso W, Lo W, Harris NS. Improved sensitivity of Lyme disease Western blots prepared with a mixture of Borrelia burgdorferi strains 297 and B31. Chronic Dis Int. 2014;1:7.

27. Ma B, Christen B, Leung D, Vigo-Pelfrey C. Serodiagnosis of Lyme borreliosis by Western immunoblot: reactivity of various significant antibodies against Borrelia burgdorferi. J Clin Microbiol. 1992;30(2): 370-376.

28. Engstrom SM, Shoop E, Johnson RC. Immunoblot interpretation criteria for serodiagnosis of early Lyme disease. J Clin Microbiol. 1995;33(2): 419-427.

29. Brorson O, Brorson SH. Transformation of cystic forms of Borrelia burgdorferi to normal mobile spirochetes. Infection. 1997;25(4): 240-246.

30. Murgia R, Cinco M. Induction of cystic forms by different stress conditions in Borrelia burgdorferi. APMIS. 2004;112(1):57-62.

31. MacDonald AB. Borrelia burgdorferi tissue morphologies and imaging methodologies. Eur J Clin Microbiol Infect Dis. 2013;32(8):1077-1082.

32. Stricker RB, Johnson L. Borrelia burgdorferi aggrecanase activity: more evidence for persistent infection in Lyme disease. Front Cell Infect Microbiol. 2013;3:40.

33. Meriläinen L, Herranen A, Schwarzbach A, Gilbert L. Morphological and biochemical features of Borrelia burgdorferi pleomorphic forms. Microbiology. 2015;161(Pt 3):516-527.

34. Timmaraju VA, Theophilus PA, Balasubramanian K, Shakih S, Luecke DF, Sapi E. Biofilm formation by Borrelia burgdorferi sensu lato. FEMS Microbiol Lett. 2015;362(15):fnv120.

35. Sharma B, Brown AV, Matluck NE, Hu LT, Lewis K. Borrelia burgdorferi, the causative agent of Lyme disease, forms drug-tolerant persister cells. Antimicrob Agents Chemother. 2015;59(8):4616-4624.

36. Feng J, Wang T, Shi W, Zhang S, Sullivan D, Auwaerter PG, Zhang Y. Identification of novel activity against Borrelia burgdorferi persisters using an FDA approved drug library. Emerg Microbes Infect. 2014; 3(7):e49.

37. Wikipedia 2015. Antibiotic timeline. Available from: https://en. wikipedia.org/wiki/Timeline_of_antibiotics. Accessed July 9, 2016.

38. Sloan DJ, Lewis JM. Management of multidrug-resistant TB: novel treatments and their expansion to low resource settings. Trans $R$ Soc Trop Med Hyg. 2016;110(3):163-172.

39. Ghosh AK, Osswald HL, Prato G. Recent progress in the development of HIV-1 protease inhibitors for the treatment of HIV/AIDS. J Med Chem. 2016;59(11):5172-5208.

40. Zhang X. Direct anti-HCV agents. Acta Pharm Sin B. 2016;6(1): 26-31.

41. Steimer L, Klostermeier D. RNA helicases in infection and disease. RNA Biol. 2012; 9(2):751-771.

42. Leitão AL, Costa MC, Enguita FJ. Unzippers, resolvers and sensors: a structural and functional biochemistry tale of RNA helicases. Int $\mathrm{J} \mathrm{Mol}$ Sci. 2015;16(2):2269-2293.

43. Feng J, Shi W, Zhang S, Zhang Y. Persister mechanisms in Borrelia burgdorferi: implications for improved intervention. Emerg Microbes Infect. 2015;4(8):e51. 
44. Gherardini FC. Borrelia burgdorferi HtrA may promote dissemination and irritation. Mol Microbiol. 2013;90(2):209-213.

45. Russell TM, Tang X, Goldstein JM, Bagarozzi D, Johnson BJ. The saltsensitive structure and zinc inhibition of Borrelia burgdorferi protease BbHtrA. Mol Microbiol. 2016;99(3):586-596.

46. Coleman JL, Katona LI, Kuhlow C, Toledo A, Okan NA, Tokarz R, Benach JL. Evidence that two ATP-dependent (Lon) proteases in Borrelia burgdorferi serve different functions. PLoS Pathog. 2009; 5(11):e1000676.

47. Kumru OS, Bunikis I, Sorokina I, Bergstrom S, Zuckert WR. Specificity and role of the Borrelia burgdorferi CtpA protease in outer membrane protein processing. J Bacteriol. 2011;193(20):5759-5765.
48. Salman-Dilgimen A, Hardy P-O, Radolf JD, Caimano MJ, Chaconas G. HrpA, an RNA helicase involved in RNA processing, is required for mouse infectivity and tick transmission of the Lyme disease spirochete. PLoS Pathog. 2013;9(12):e1003841.

49. Arnold WK, Savage CR, Antonicello AD, Stevenson B. Apparent role for Borrelia burgdorferi LuxS during mammalian infection. Infect Immun. 2015;83(4):1347-1353.

50. Chu C-Y, Stewart PE, Bestor A, et al. Function of the Borrelia burgdorferi $\mathrm{FtsH}$ homolog is essential for viability both in vitro and in vivo and independent of HflK/C. mBio 2016;7(2):e00404-16.

51. Khoury JD. The evolving potential of companion diagnostics. Scand $J$ Clin Lab Invest Suppl. 2016;245:S22-S54.
Infection and Drug Resistance

\section{Publish your work in this journal}

Infection and Drug Resistance is an international, peer-reviewed openaccess journal that focuses on the optimal treatment of infection (bacterial, fungal and viral) and the development and institution of preventive strategies to minimize the development and spread of resistance. The journal is specifically concerned with the epidemiology of antibiotic

\section{Dovepress}

resistance and the mechanisms of resistance development and diffusion in both hospitals and the community. The manuscript management system is completely online and includes a very quick and fair peerreview system, which is all easy to use. Visit http://www.dovepress.com/ testimonials.php to read real quotes from published authors.

Submit your manuscript here: https://www.dovepress.com/infection-and-drug-resistance-journal 